Nuntius Antiquus, Belo Horizonte, v. 13, n. 2, p. 59-73, 2017

\title{
Dilemas textuais na tradução crítica da República de Platão
}

\section{Textual Dilemmata in a Critical Translation of Plato's Republic}

\author{
Rodolfo Nunes Lopes \\ Departamento de Filosofia \\ Universidade de Brasília, Brasília, Distrito Federal / Brasil \\ rodolfo.nunes.lopes@gmail.com
}

Resumo: O presente texto diz respeito a alguns dilemas de tradução da República de Platão, os quais resultam directamente de problemas relativos ao estabelecimento do texto. O propósito destas páginas é, pois, fixar as coordenadas básicas que nos possibilitem circular pelo terrível labirinto da tradição textual deste diálogo, isto é, os princípios e critérios que permitam fundamentar e justificar as opções de tradução mais discutíveis, porquanto dependentes de problemas textuais. A proposta metodológica para enfrentar tais aporias será exemplificada com alguns casos paradigmáticos do Livro I. Tomarei como obras de referência os resultados do projecto editorial "Text edition of Plato's eighth tetralogy", iniciado em 1977 por Siem Slings, nomeadamente o trabalho de Gerard Boter sobre a tradição textual do diálogo (BOTER, 1989) e as notas de crítica textual publicadas por Slings entre 1998 e 2003, na revista Mnemosyne, postumamente coligidas e editadas em uma monografia enquanto suplemento dessa mesma revista (SLINGS, 2005).

Palavras-chave: Platão; República; problemas textuais; Livro I.

Abstract: This article deals with some textual problems of Plato's Republic that are relevant for a Portuguese translation of this dialogue. The purpose of these pages is to determine the main principles and criteria that will allow me to justify some translations difficulties caused by textual problems. This methodology will be exemplified with some textual problems of Book I. The reference materials are those published under the project "Text edition of Plato's eighth tetralogy" organized by Siem Slings from 1977 to 2003. The main works will be study of Gerard Boter on the textual tradition (BOTER, 1989) and the critical notes published by Slings in Mnemosyne, which were posthumously published as a supplement of that journal (SLINGS, 2005).

Keywords: Plato; Republic; textual problems; Book I. 


\section{Introdução}

O presente texto diz respeito a alguns dilemas de tradução da República de Platão, os quais resultam directamente de problemas relativos ao estabelecimento do texto. O propósito destas páginas é, pois, fixar as coordenadas básicas que nos possibilitem circular pelo terrível labirinto da tradição textual deste diálogo, isto é, os princípios e critérios que permitam fundamentar e justificar as opções de tradução mais discutíveis, porquanto dependentes de problemas textuais. A proposta metodológica para enfrentar tais aporias será exemplificada com alguns casos paradigmáticos do Livro I. Visto que tomo por critério soberano a inteligibilidade do texto em língua portuguesa, não terei em conta os casos que não tenham influência na tradução final.

Tomarei como obras de referência os principais resultados do projecto editorial "Text edition of Plato's eighth tetralogy", iniciado em 1977 por Siem Slings, cujo primeiro fruto foi a tese de doutorado do próprio Slings sobre o texto do Clitofonte (1981), mais tarde publicada em formato de livro (SLINGS, 1999). Os principais frutos viriam a ser (1) a monumental obra de Gerard Boter sobre a tradição textual da República (BOTER, 1989), que resultara da sua tese de doutorado orientada por Slings; (2) as notas de crítica textual (exclusivamente dedicadas à República), publicadas como artigos por Slings, entre 1998 e 2003, na revista Mnemosyne, e postumamente coligidas em uma monografia publicada como suplemento dessa mesma revista (SLINGS, 2005); (3) a edição crítica do texto da República, publicada por Slings, em 2003, na canónica Oxford Classical Texts.

Devo desde logo sublinhar que seria abusivo sugerir que a edição de Slings deva simplesmente substituir a de Burnet $(1902,1905)-o$ facto de aquela ter sido publicada quase 100 anos depois desta, na mesma editora, poderia, por si só, sugeri-lo. Como veremos em seguida - não só pelo facto de o texto de Burnet representar a síntese dos resultados da crítica textual da República até então mas também pela infeliz circunstância de não terem surgido novas fontes primárias relevantes (embora os papiros descobertos, entretanto, sejam importantes, eles não acrescentam nada de substancial aos manuscritos já conhecidos) -, seria 
obviamente impossível que a edição de Slings inaugurasse um novo paradigma de leitura. Por mais rigoroso e exaustivo que tenha sido esse monumental trabalho, continuam a colocar-se muitos problemas textuais para cuja solução a tradição conhecida (directa ou indirecta) se revela tristemente insatisfatória. Nesses casos, o intérprete do texto é obrigado a recorrer a uma certa dose de criatividade para restituir o sentido do texto. Em todo o caso, a edição de Slings representa a síntese do maior estudo alguma vez já feito sobre o texto da República; e por "estudo" entenda-se as quase três décadas de pesquisa dedicadas a esse diálogo. Depois desses resultados, o estudioso tem à sua disposição todas as ferramentas necessárias para abordar esses problemas e, claro, tomar uma posição que permita tornar o texto inteligível, a qual, ao mesmo tempo, seja minimamente justificável. Por esse motivo, tomarei como materiais de referência as obras de Boter (1989) e Slings (2003; 2005), no que respeita tanto aos detalhes convencionais (siglas dos manuscritos, paginação etc.) quanto aos principais pressupostos de estabelecimento e reconstituição do texto.

Convém notar que, até o trabalho de Boter (1989), não existia nenhum estudo exclusivamente dedicado à tradição textual da República. Todas as publicações que abordavam a questão o faziam acidentalmente, fosse por se inserirem em estudos sobre toda a tradição textual de Platão, fosse por incidirem em um determinado manuscrito que incluía o diálogo (vide Boter, 1989, p. 17-22; Pasquali, 1962, 247-sqq). As consequências de tal dispersão eram, no essencial, as seguintes: não estavam reconhecidas as fontes primárias, havendo unanimidade apenas sobre dois manuscritos e muita polémica sobre outros dois; vários manuscritos secundários eram completamente desconhecidos, e os poucos conhecidos até então não eram valorizados na reconstrução do texto; o levantamento da tradição indirecta era demasiado limitado; a tradição papirológica era ainda mais limitada. Quanto aos resultados principais do estudo, voltarei a esse assunto em seguida, depois de ter reconstituído (muito resumidamente) a historiografia das edições modernas da República até o projecto de Slings. 


\section{Historiografia das edições críticas da República}

A primeira edição crítica do texto da República, tendo em conta os padrões modernos da crítica textual, é a de Immanuel Bekker (1817). ${ }^{1}$ Até aqui, eram utilizadas as edições renascentistas, mormente a de Stephanus, tradicionalmente conhecida como a vulgata de Platão. Tendo em conta os padrões modernos, o texto de Stephanus deve ser considerado globalmente inaceitável, na medida em que se limita a cotejar as (precárias) edições impressas precedentes, sem que tenha consultado um único manuscrito (vide Boter, p. 247-251). Bekker foi o primeiro a cotejar um número considerável de manuscritos (12 no total, enquanto as anteriores usavam, no máximo, seis); mas, acima de tudo, foi o primeiro a reconhecer maior autoridade de $\mathbf{A}$ em relação aos restantes manuscritos, uma tendência que perdurou até as edições britânicas produzidas na virada para o séc. XX. A de Ast, mesmo na terceira edição (1822), não acrescenta nenhum outro manuscrito. Stallbaum, na primeira edição (1825), acrescenta os chamados manuscritos Florentinos, todos eles secundários (a, b, c, $\mathbf{n}, \mathbf{x}, \boldsymbol{\alpha}, \boldsymbol{\beta}, \boldsymbol{\gamma}$ ); e na segunda (1829) inclui alguma tradição indirecta. A de Schneider (1830-1833), a mais completa e rigorosa até a data, embora continue a pressupor a supremacia de $\mathbf{A}$, reconhece autoridade acrescida a $\mathbf{D}$ e $\mathbf{F}$, sendo, pois, a primeira edição, ainda que acidentalmente, a ser baseada no que hoje sabemos serem as fontes primárias da República (ADF). As de Baiter, Orelli e Winckelmann (1840) e Hermann (1852) são integralmente baseadas nas de Bekker, Stallbaum e Schneider (sobretudo na deste último).

Nos 11 anos decorridos entre 1894 e 1905 foram produzidas na Inglaterra quatro edições críticas da República. A primeira, e mais importante de todas, foi a de Jowett e Campbell (1894), não só por oferecer uma tão vasta quanto inédita descrição crítica da tradição textual mas também, e sobretudo, por disputar a supremacia de A em relação aos

\footnotetext{
${ }^{1}$ Note-se que a vetusta e veneranda edição crítica de Bekker inclui todas as obras de Platão, publicadas em oito volumes entre 1816 e 1818; a estes oito foram acrescentados outros dois, em 1823, com comentários e notas críticas ao texto (BEKKER, 1823). O texto da República foi incluído no segundo volume (1817).
} 
outros manuscritos (unanimemente aceite desde Bekker), argumentando que $\mathbf{D}$ e $\mathbf{M}$ representavam famílias diferentes - hoje sabemos que $\mathbf{M}$ é, na verdade, uma cópia de A, mas Jowett e Campbell foram os primeiros a abandonar a pretensa supremacia de $\mathbf{A}$ e a propor três famílias para as fontes primárias, tendo fixado corretamente as primeiras duas (A e D). As duas edições de Adam (1897, 1902), cuja principal diferença consiste no extenso comentário incluído na segunda, aceitam, tal como Campbell, o estatuto primário dos manuscritos A e D, mas, ao contrário de Campbell, não reconhecem tal estatuto a $\mathbf{M}$ - a tendência geral de Adam, aliás, é (1) seguir A; (2) optar por D, quando A está errado; (3) optar por qualquer um dos outros manuscritos (sobretudo E e q), quando A e D estão errados; e (4) recorrer à tradição indirecta quando os manuscritos (primários e secundários) se revelam insuficientes. Quanto à de Burnet, publicada originalmente em 1902 (apenas com a República) e depois inserida no IV volume (1905) dos Platonis Opera, pelo facto de constituir a vulgata moderna de Platão, merece ulteriores considerações.

A principal inovação da edição de Burnet foi atribuir a $\mathbf{F}$ o estatuto de fonte primária. Na verdade, o trabalho de Burnet, que não chegou a cotejar directamente os manuscritos (seguiu os resultados de Adam e Campbell para A, de Campbell para D e M, e o de Schneider para $\mathbf{F}$ ), consistiu na reinterpretação das edições anteriores com base no pressuposto (já intuído por Schneider) que $\mathbf{F}$ era a quarta fonte primária. As outras três seriam ADM, conforme demonstrado pela classificação de Campbell. O problema desta proposta, amplamente criticada por Adam (1902), Stuart Jones (1902) e Immisch (1903), foi ter sustentado, de um modo exageradamente especulativo, que $\mathbf{F}$ derivava de um arquétipo muito mais antigo do que qualquer outro manuscrito platónico. Fundandose na manifesta tendência de $\mathbf{F}$ concordar com a tradição indirecta, Burnet sugere, também neste ponto inspirado em Schneider, que este manuscrito deriva de uma suposta veterem vulgatam (como diz na p. 2 do prefácio à sua edição), isto é, de uma versão antiga utilizada por autores como Estobeu e Eusébio. Ainda que hoje reconheçamos equivocada tal ousada proposta, é certo que o texto de Burnet tem a vantagem de reconhecer como primárias as fontes que hoje sabemos serem, de facto, primárias 
(ADF); ainda que tenha incluído uma quarta (M), que hoje sabemos ser, na verdade, derivada de $\mathbf{A}$.

Desde a vulgata de Burnet até o projecto de Slings, surgiram algumas edições que, apesar de não introduzirem novidades e de continuarem a seguir uma classificação equivocada dos manuscritos, merecem uma breve nota neste conspecto: a de Chambry, incluída nos volumes de Platão na clássica Budé/Les Belles Lettres (1932-1934), considera AF fontes primárias e defende que $\mathbf{D}$ seria uma contaminação de $\mathbf{A F}$ (facto impossível, dado que $\mathbf{F}$ é dois séculos posterior a $\mathbf{D}$ ), bem como sobrevaloriza fontes secundárias como T, W, E e q, embora inclua a novidade de referir a tradição papirológica (na época conheciam-se apenas quatro); a de Pabón e Galiano, publicada em Espanha em 1949, que segue maioritariamente $\mathbf{A}$, ainda na senda das edições germânicas (principalmente Schneider).

Finalmente, a edição de Slings (2003), que, conforme vimos anteriormente, apresenta poucas divergências substanciais em relação ao texto de Burnet, tem por principais virtudes (1) a riqueza do aparato crítico (podemos considerá-lo perfeitamente completo) e, sobretudo, (2) a classificação das fontes textuais. Pela primeira vez, a República é editada (1) com toda a tradição indirecta conhecida até então (incluindo traduções árabes, coptas e hebraicas, alusões, escólios etc.) e (2) segundo um estudo exaustivo sobre a transmissão do texto. Para tais resultados foi, obviamente, fundamental o monumental trabalho de Boter sobre a tradição textual do diálogo (BOTER, 1989).

\section{Critérios para análise dos problemas textuais}

Antes de fixar os critérios que sigo para a classificação dos problemas textuais relevantes para a tradução do texto, devo antes de mais referir as principais conclusões do estudo de Boter (1989), as quais tomo por pressupostos de análise. A explicação detalhada das justificações excederia em muito o limite e o alcance destas páginas, pelo que me limitarei a indicar as páginas em que o autor demonstra cada uma das conclusões, indicando apenas as razões que as fundamentam. Em primeiro lugar, relembremos que, até Boter, tínhamos quatro fontes 
primárias (ADFM), sendo que tal estatuto era (1) unanimemente atribuído a duas delas (AF) e (2) muito discutido em relação às outras duas (DM) - Chambry rejeitara D; Campbell e Burnet consideravam M gémeo de A, mas esta posição foi rejeitada por Adam e Chambry. Boter irá demonstrar que: (1) $\mathbf{M}$ deriva de $\mathbf{A}$, tendo em conta que $\mathbf{M}$ incorpora a quase totalidade das correções inseridas em A por copistas posteriores (BOTER, 1989, p. 113-116); que ADF constituem famílias independentes (BOTER, 1989, p. 65-80), sendo que (1) A segue linea recta até a Antiguidade (pela elevada percentagem de (1) concordâncias com a tradição indirecta e de (2) corrupções derivadas de erros na conversão das unciais antigas, característica própria dos arquétipos antigos), que (2) DF têm a mesma fonte, mas diferente da de A (pela elevada percentagem de erros em DF não presentes em A) e que (3) DF, apesar de terem a mesma fonte, constituem famílias diferentes (pelo facto de cada um deles demonstrar uma contaminação completamente independente do outro). Em suma, a conclusão principal da classificação dos manuscritos por Boter demonstra que ADF (1) são as fontes primárias (todos os outros manuscritos derivam de um destes); (2) podem ser reconduzidos ao mesmo arquétipo (bem posterior a Platão); (3) são, em todo o caso, independentes uns dos outros.

Tendo, então, em vista as principais conclusões de Boter, tentarei agora esclarecer os critérios mediante os quais analisarei os problemas textuais da República.

O principal, como já foi referido, diz respeito à tradução, ou seja, terei apenas em conta os problemas textuais que tenham influência no sentido da tradução. Assim, estarão excluídos os que dizem respeito à pontuação e a variações de partículas ou construções gramaticais que não alteram o sentido do texto em português. Por exemplo, em 330c5,

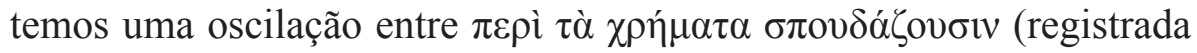

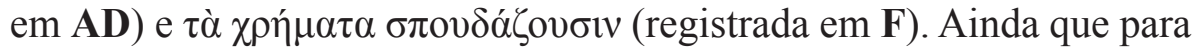
um editor crítico tal oscilação configure um problema textual, ele não

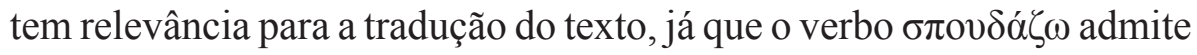
acusativo simples ou $\pi \varepsilon \rho i ́$ com acusativo (além de que Platão utiliza indiscriminadamente ambas as construções); ou seja, a tradução será sempre "interessam-se pelas riquezas". 
O segundo critério depende directamente da supremacia de ADF (demonstrada por Boter) em relação aos restantes manuscritos - todos eles ipso facto secundários. Assim, para que uma determinada variante textual constitua um problema textual, terá que implicar uma discordância entre ADF. Tanto quanto nos é possível saber, não existe um critério para reconhecer mais autoridade a um desses três manuscritos. Embora A tenha sido sobrevalorizado pela maioria dos editores modernos, pelo facto de ser o mais antigo (de todo o corpus Platonicum) e de, muito provavelmente, seguir linea recta até a Antiguidade (isto é, sem depender de um arquétipo bizantino), existem muitos casos em que a variante registrada em $\mathbf{D}$ ou $\mathbf{F}$ (ou ambos) deve ser preferida à de $\mathbf{A}$. Ironicamente, as mesmas razões que demonstram a antiguidade de $\mathbf{A}$ servem também para demonstrar que este manuscrito não deve ser considerado mais fiel per se do que $\mathbf{D}$ e $\mathbf{F}$, como, por exemplo, (1) os casos em que $\mathbf{A}$ e a tradição indirecta concordam no mesmo erro; (2) algumas confusões no desdobramento das maiúsculas antigas (casos clássicos como $\Pi / T$, П/TI, $\Delta \mathrm{EI} / \mathrm{AEI}, \mathrm{E} / \Sigma$ ); ou (3) alguns erros na divisão das palavras, que, como é sabido, figuravam sem espaços nos arquétipos antigos (e.g.

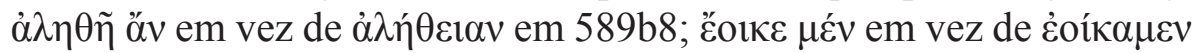
em 595b10). Por esse motivo, considero que os três manuscritos que constituem as fontes primárias têm a mesma autoridade, de tal forma que a versão registrada por qualquer um deles tem iguais condições de ser considerada válida.

O terceiro critério, aplicável apenas a um reduzido número de problemas, diz respeito aos casos em que ADF registram uma versão manifestamente incompatível com os princípios linguísticos básicos (gramaticais e pragmáticos) do Grego Ático. A solução de tais problemas passa, em primeira instância, por recorrer (1) aos manuscritos secundários; (2) às correções introduzidas pelos copistas na margem ou entrelinha do documento que estavam copiando (as chamadas "mãos tardias"); (3) à tradição indirecta; e (4) a ocorrências da construção/ expressão em causa no corpus Platonicum e, no limite, em outros autores áticos. Caso nenhuma dessas fontes registre uma opção satisfatória, a alternativa será pressupor uma corrupção textual impossível de rastrear e ipso facto impassível de ser explicada. Nesses "casos-limite", limito-me 
a providenciar uma tradução mais "livre", a qual será fundamentada (1) em uma variante textual minimamente justificável (à luz dos referidos critérios) e (2) no contexto dramático-argumentativo em que tal problema ocorre.

\section{Alguns dilemas de tradução do Livro I}

Os casos que irei analisar nas páginas seguintes são apenas alguns exemplos. A sua apresentação e discussão estão, pois, longe de serem exaustivas, mesmo tendo apenas em conta o Livro I. De modo a facilitar a leitura, organizei os dados de cada problema de acordo com os seguintes tópicos:

- breve descrição do contexto dramático-argumentativo;

- citação da passagem em que ocorre o problema, indicando entre [] as variantes elegíveis;

- traduções possíveis da passagem segundo cada uma das variantes;

- $\quad$ análise do problema textual;

- $\quad$ escolha da versão mais plausível.

327c10 Depois de ter descido ao Pireu, Sócrates tenta regressar a Atenas, mas é impedido pelo grupo de Polemarco.

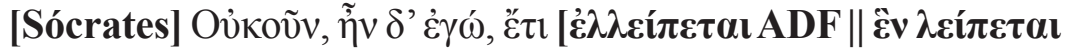

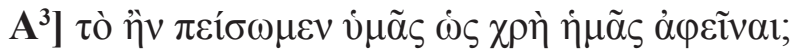

ADF: Então, disse eu, ainda nos falta convencer-vos de que nos devem deixar ir embora.

$\mathbf{A}^{3}$ : Então, disse eu, ainda nos resta uma possibilidade: convencer-vos de que nos devem deixar ir embora.

Pelos critérios que expus anteriormente, este caso não constituiria um problema textual, dado que nem existe discordância entre ADF nem a concordância implica um problema linguístico. O problema é que uma parte considerável dos editores modernos (e.g. Jowett \& Campbell, Adam e Burnet) adopta a correção de $\mathbf{A}^{\mathbf{3}}$ - uma mão tardia que interveio 
consideravelmente em A; vide Boter (1989, p. 45). Na verdade, não me parece existir nenhum problema linguístico com a construção غ̇ $\lambda \lambda \varepsilon i ́ \pi \varepsilon \tau \alpha$, com o artigo neutro a determinar toda a proposição seguinte. Não só o uso do artigo (na forma singular neutra) para determinar uma proposição inteira é uma característica do grego ático - vide Humbert (1997, p. 56); e.g. E. Hipp. 264; X. Cyr. 5.1 .21 mas também - como notou

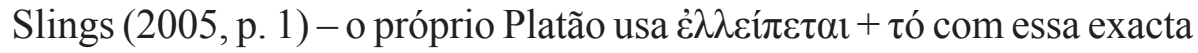
função (Phlb. 18d).

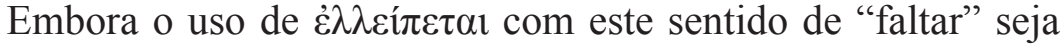
pouco frequente (o clássico $L S J$ não chega a registrá-lo), parece-me estar em causa, do ponto de vista estilístico, um eco de um dos sentidos

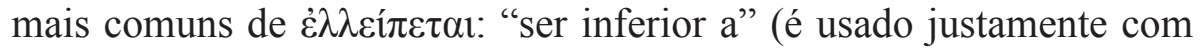
esse sentido mais adiante, em 484d). Está em causa a inferioridade de Sócrates e Gláucon perante Polemarco e os outros, anunciados como

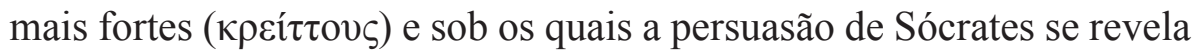
totalmente ineficaz. Embora tal interpretação possa ser abusiva, creio que não seja de todo incompatível com as ambiguidades semânticas que marcam o estilo de Platão.

Opto, pois, pela versão de ADF.

330e5: Céfalo, por estar já perto da morte, passa a temer as "estórias que se contavam sobre o Hades" (330d), nomeadamente as penas destinadas a quem procedeu mal durante a vida.

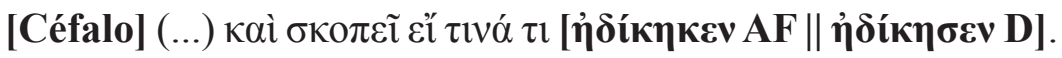
AF: E procura saber se cometeu alguma injustiça com alguém. D: E procura saber se praticou alguma injustiça com alguém.

A divergência morfológica entre as duas variantes é mínima (AF registra um perfeito, e D um aoristo), mas as implicações na tradução justificam considerar esse problema textual. Se levarmos a sério as subtilezas semânticas latentes na escolha entre aqueles dois tempos verbais, a escolha recairá na variante de $\mathbf{A F}$, pois o perfeito costuma implicar responsabilidade do agente (CHANTRAINE, 1927, 177 apud SLINGS, 2005, p. 3); além de que normalmente designa uma ação que 
termina no presente, mas depende de uma série de eventos iniciada necessariamente no passado. Tendo em conta que se trata das injustiças que Céfalo teme ter cometido até então, o perfeito seria sem dúvida o recurso linguístico mais apropriado. Tendo em conta tais subtilezas linguísticas, sobretudo a noção de responsabilidade do agente contida no uso do perfeito, decido por traduzir $\alpha \dot{\delta} 1 \kappa \varepsilon ́ \omega$ por "cometer injustiças" em vez de "praticar injustiças".

Opto, pois, pela versão de AF.

\section{5a8: Sócrates refuta a definição de "justo" proposta por Polemarco ("justo" é fazer bem aos amigos e mal aos inimigos).}

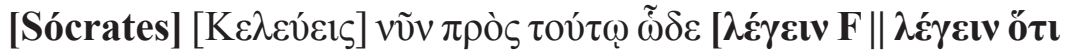

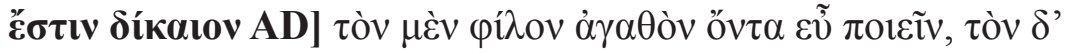

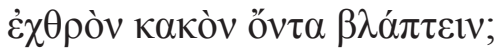

F: [Queres] então agora também dizer para fazer bem ao amigo que é bom e para tratar mal o inimigo que é mau?

AD: [Queres] então agora acrescentar que é justo fazer bem ao amigo que é bom e tratar mal o inimigo que é mau?

Note-se, em primeiro lugar, que o problema em causa implica optar por uma de duas estruturas sintáticas completamente diferentes.

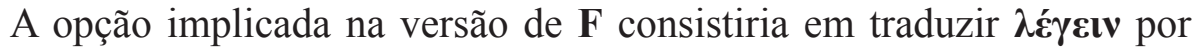

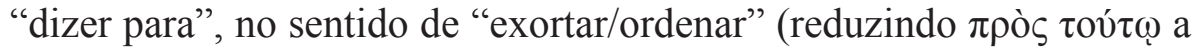

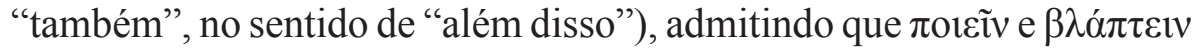
são conjuntamente determinados por $\lambda \dot{\varepsilon} \gamma \varepsilon \mathbf{v}$. Por outro lado, a opção implicada na versão de AD resulta em uma sintaxe, a meu ver, mais

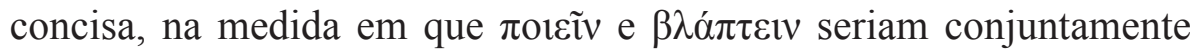

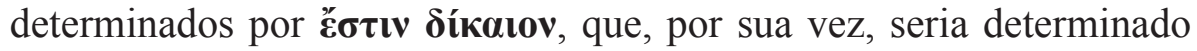
por $\lambda \boldsymbol{\varepsilon} \gamma \varepsilon \mathbf{l}$ por meio da clássica construção com ő $\tau \mathbf{l}$ (neste caso, a

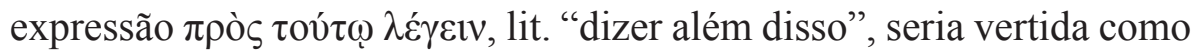
“acrescentar”). Ademais, convém notar que a versão de F implicaria eliminar uma porção considerável de texto que aparece registrada na esmagadora maioria da tradição textual; e, de acordo com os princípios mais básicos da crítica textual, a eliminação de texto exige argumentos 
fortes. A verdade é que não encontro nenhum argumento suficientemente forte para elidir aquelas três palavras, enquanto que os argumentos que considero mais fortes aconselham a mantê-las.

Opto, pois, pela versão de AD.

\section{1e7: a medicina foi criada para solucionar problemas que o corpo naturalmente virá a ter.}

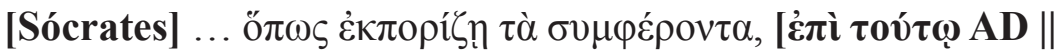

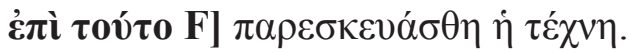

AD: Para providenciar o que é conveniente [ao corpo]; foi por isso que se desenvolveu esta arte.

F: Para providenciar o que é conveniente [ao corpo]; foi para isso que se desenvolveu esta arte.

A diferença entre as duas variantes possíveis é assaz discreta, tanto no que respeita à estrutura morfossintática quanto em relação às implicações para a tradução do texto. Está, todavia, em causa uma nuance de sentido particularmente interessante do ponto de vista etiológico e uma questão de consecutio entre as duas proposições (formuladas de um modo manifestamente paratático, deve dizer-se).

Gramaticalmente, ambas as hipóteses são aceitáveis, dado que a preposição éđí pode formar sintagmas com qualquer um dos três casos oblíquos. No caso, a opção será entre uma expressão de causa (o dativo registrado em AD) e uma expressão de fim (o acusativo registrado em F). Tendo em conta que a primeira proposição constitui uma das mais clássicas construções de fim (ö $\pi \omega \varsigma$ com subjuntivo), e tendo em conta o princípio da consecutio, considero mais plausível a construção com acusativo, que mantém essa mesma noção de finalidade. Além disso, tal opção parece estar mais de acordo com o estilo platónico, na medida em que a construção $\pi \alpha \rho \varepsilon \sigma \kappa \varepsilon v \alpha ́ \zeta \omega$ com éđì e acusativo (com sentido de fim) aparece duas vezes no Górgias (509e1, 510a3) e uma outra na própria República (422d7), enquanto que a estrutura correspondente com dativo nunca é utilizada ao longo de todo o corpus Platonicum.

Opto, pois, pela versão de $\mathbf{F}$. 


\section{4e1: Sócrates tenta impedir a retirada de Trasímaco, argumentando que a sua definição de justiça implica uma conduta de vida; e, por isso, deve ser discutida.}

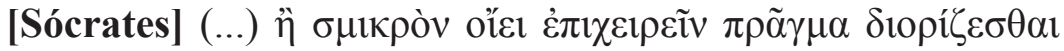

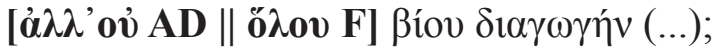

F: Ou parece-te um assunto insignificante tentar definir uma conduta para a vida toda $(. .$.$) ?$

AD: Ou parece-te insignificante tentar definir o assunto, mas não [te parece insignificante] uma conduta para a vida (...)?

Tal como em $335 \mathrm{a} 8$ (vide supra), as duas variantes possíveis implicam duas estruturas sintáticas substancialmente diferentes. De acordo com a versão de AD, oǔ

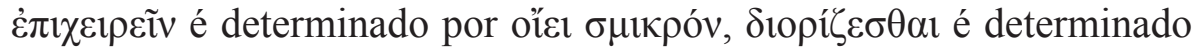

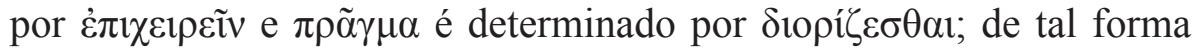

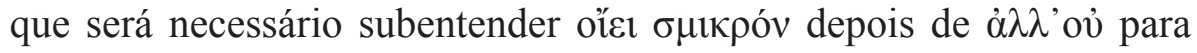

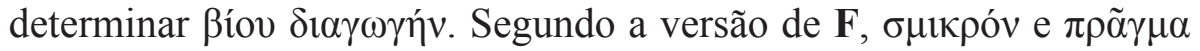

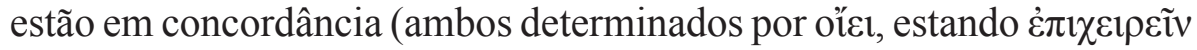
determinado por ớદı $\sigma \mu 1 \kappa \rho o ́ v ~ . . . ~ \pi \rho \tilde{\alpha} \gamma \mu \alpha$, e $\delta 10 \rho i ́ \zeta \varepsilon \sigma \theta \alpha$ determinado

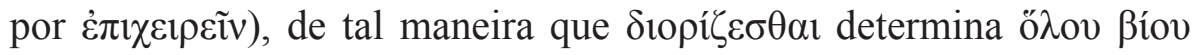
$\delta ı \gamma \omega \gamma \eta ́ v$. Do ponto de vista estrictamente gramatical, ambas as estruturas sintácticas são aceitáveis. No entanto, se, por um lado, a opção resultante de AD exige um ligeiro esforço de criatividade sintática (pelo facto de ser

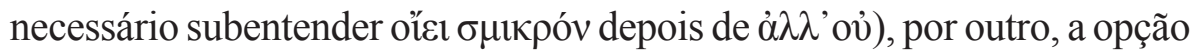
resultante de $\mathbf{F}$ se afigura mais plausível do ponto de vista semântico, ao pressupor a ideia de que a "conduta" ( $\delta 1 \alpha \gamma \omega \gamma \eta \dot{v})$ em causa diz respeito a "toda a vida" (ő $\lambda$ ov ßíov) - o que me parece estar em perfeito acordo com a conclusão do diálogo, mais especificamente no mito escatológico do Livro X, segundo o qual as almas serão julgadas pelas ações praticadas ao longo de toda a vida.

Opto, pois, pela versão de $\mathbf{F}$. 


\section{Referências}

ADAM, J. The Republic of Plato. Cambridge: Cambridge University Press, 1897.

ADAM, J. The Republic of Plato. Edited with Critical Notes, Commentary and Appendices. Cambridge: Cambridge University Press, 1902.

AST, F. Platonis Politia sive de Republica libri decem. Ienae: Croecerianis, 1804.

AST, F. Platonis Politia sive de Republica libri decem. Lipsiae: Benjamin Schwickert, 1814.

AST, F. Platonis quae exstant opera, IV-V. Lipsiae: Libraria Weidmannia, 1822.

BAITER, J.; ORELLI, J.; WINCKELMANN, A. Platonis opera omnia, XIII. Turici: Meyeri \& Zelleri, 1840.

BEKKER, I. Platonis dialogi, III.1. Berolini: Reimer, 1817.

BEKKER, I. Commentaria critica in Platonem a se editum. Berolini: Reimer, 1823.

BOTER, G. The Textual Tradition of Plato's Republic. Leiden: Brill, 1989.

BURNET, J. Platonis opera, v. IV. Oxonii: E Typographeo Clarendoniano, 1905.

BURNET, J. Platonis Respublica. Oxonii: E Typographeo Clarendoniano, 1902.

CHAMBRY, E. Platon, Oeuvres complètes, VI-VII. Paris: Les Belles Lettres, 1932-1934.

CHANTRAINE, P. Histoire du Parfait Grec. Paris: Champion, 1927.

HERMANN, C. Platonis Dialogi, IV. Lipsiae: Teubner, 1852.

HUMBERT, J. Syntaxe Grecque. 3. ed. Paris: Klincksieck, 1997.

JOWETT, B.; CAMPBELL, L. The Republic of Plato. Oxford: Oxford University Press, 1894. 
PABÓN, J.; GALIANO, M. La República. Madrid: Instituto de Estudios Politicos, 1949.

PASQUALI, G. Storia della tradizione e critica del testo. Firenze: Felice Le Monnier, 1962.

SCHNEIDER, C. Platonis opera Graece. Lipsiae: B.G. Teubneri et F. Clavdii, 1830-1833.

SLINGS, S. Plato: Clitophon, Edited with Introduction, Translation and Commentary. Cambridge: Cambridge University Press, 1999.

SLINGS, S. Platonis Respublica. Oxonii: E Typographeo Clarendoniano, 2003.

SLINGS, S. Critical Notes on Plato's Politeia. Leiden/Boston: Brill, 2005.

STALLBAUM, G. Platonis quae supersunt opera, III. Leipzig: J. Weigelii, 1825.

STALLBAUM, G. Platonis dialogos selectos, III.1-2. Gothae-Erfordiae: Hennings, 1829.

STEPHANVS, H. Platonis opera quae exstant omnia. [Genevae]: Henricus Stephanus, 1578.

Recebido em 30 de julho de 2017. Aprovado em 10 de setembro de 2017. 